\title{
Smart Cities: Transport Challenges of the Macedonian Capital City
}

\author{
Mimoza Bogdanoska, JOVANOVSKA, \\ Faculty of Information and Communication Technologies - Bitola, St. Kliment Ohridski University in Bitola, \\ Partizanska bb, Bitola, 7000, Republic of Macedonia, \\ mimoza.jovanovska@fikt.edu.mk \\ Daniela Koltovska, NECHOSKA, \\ Faculty of Technical Science - Bitola, St. Kliment Ohridski University in Bitola, \\ Makedonska Falanga 33, Bitola, 7000, Republic of Macedonia, \\ daniela.koltovska@tfb.uklo.edu.mk
}

\begin{abstract}
Smart City as a concept presupposes using new information and communication technologies in order to improve the quality of life within a particular geographic area. There are six different pillars in the frame of this concept and their one purpose is to achieve better efficiency of city operations. Smart mobility and transport are some of them. The efforts of traditional cities to become smart are not easily and quickly achievable. Numerous traffic solutions have already been implemented in different cities all over the world that make the 'jump' from traditional city to smart city. This paper provides an overview of the 'smart' transport solutions that have been implemented in the city of Skopje as a traditional city, which is on its way to becoming a smart city.

The presented smart solutions are related to traffic management and control area and are aimed at alleviating traffic problems. The focus is on non-motorized solutions, e-vehicles, adaptive traffic control systems and public transport solutions. Several aims have been set in this paper - to promote the achievements of the municipality of Skopje aimed at transforming Skopje into a smart city in a transport area; to present its functionality, and to point out the disadvantages related to law regulations and the interconnection of all stakeholders involved. Finally, the idea is to provide a starting point for future research and to recommend future steps in this direction in the city of Skopje.
\end{abstract}

Keywords: smart mobility; smart government; transport solutions

JEL Classification: O3, R11, R4. 


\section{Introduction}

The global trend of increasing concentration of the population in large cities creates many challenges related to the planning, development, and operation of cities. A rapid transition to a highly urbanized population and the need to continually improve the quality of citizens' life imposes the need for high-level organization of city functionality, mainly based on collecting information, processing, and its distribution in the right place at the right time.

The technology boom, the development of the information and communication technology (ICT), which has taken place in the past few decades with the development of a new data-based system - Internet, Wireless, Bluetooth, Smart-phones, and most recently, remotely programmable machines (Volpe, 2014) has contributed to dealing with those challenges successfully. The invention of sensors, advanced control systems and the development of new algorithms allow analysis of information flow in real time which provides an improvement in the operational performances. Those new routes of functioning transform the cities from traditional to new, modern, and urban cities so called smart cities.

The difference between earlier (traditional) models of city making and smart cities is evident in the services available to citizens and commuters. Online citizen-centered services developed during the process of e-government in traditional cities, now continue to develop the smart government activities.

Driven by the general idea of smart city, this new model of city making offers on-line services in four global areas: municipal infrastructure, economic stimulus and open data, environment/energy and transport (GSMA, 2013). Each of those areas has been developing at a tremendous pace, offering a wide spectrum of citizen-centered services.

According to GSMA (2013), the field of transport leads with the largest number of projects: "99 projects of 232 mobile products and services that cover a wide variety of smart city sectors are transport related". The transformation from traditional into smart city in this area has been achieved mostly through the creation of applications for electronic ticketing, intelligent transport systems (ITS), information systems that provide traffic information in real time and using connected vehicle technology.

There are an impressive number of cities that have become smart by offering fascinating and rather practical solutions in the on-line transport 
services. The implementation of these solutions has required large volumes of investment (European Commission, Financing Models for Smart Cities, 2013). This is the reason why smart cities are located in the developed countries mostly in Europe, USA, China or Japan. Macedonia as an undeveloped country does not have a smart city yet but is on the way to get the first one - its capital, Skopje.

This paper presents the efforts that the traditional city of Skopje has been making in the process to become a smart city. Further to this introduction, the paper is organized as follows. The second section defines the concept of smart city with special emphasis of the meanings of smartness in the transport context and exploring the definitions of a smart city. The third section elaborates some examples of smart transport solutions. The fourth section elaborates the current situation in the capital of Macedonia, Skopje, regarding smart traffic solutions that have been implemented in order to decrease traffic problems. The focus is on non-motorized solutions, e-vehicles, adaptive traffic control systems and public transport solutions. The last section addresses discussion and concluding remarks.

\section{Defining Smart City}

The phrase 'smart city' dates back to the end of the last century but its popularity increased in the first decade of this 21 century. According to certain accounts, this phrase was coined in the early 1990s to illustrate how urban development was turning towards technology, innovation, and globalization (Gibson et al., 1992). According to Harrison and Donnelly (2011) "This phrase has been adopted since 2005 by a number of technology companies - Siemens (2004), Cisco (2005), IBM (2009) - for the application of complex information systems to integrate the operation of urban infrastructure and services such as buildings, transport, electrical and water distribution, and public safety".

Today, the concept of smart city is in the spotlight, so the process of its defining as well as creating of different frameworks to understand this concept is a making progress (Chourabi et al., 2012). As a result of different efforts (academic and practitioners'), a number of definitions have been produced in literature, nevertheless, "there is not a one-size-fits-all definition of smart city" (Nam, Prado, 2011). Manville et al. (2014) explain the main reason for this situation: "examples of Smart Cities come in many variants, sizes and types". In this paper, based on the already existing definitions that fit to our topic and we create own definition that fully suit our purposes. 
The primary purpose in the process of starting the realization of the smart city concept is given by the Natural Resources Defence Council: "a city (that is) striving to make itself 'smarter' (more efficient, sustainable, equitable, and liveable)". Caragliu et al. (2009) give a more descriptive definition, later on, modified by Allwinkle and Cruickshank (2011): "a city is smart when investments in human/social capital and traditional and modern ICT infrastructure fuel sustainable economic growth and enhance a quality of life, with a wise management of natural resources through participatory governance", where "the modern e-government 'citizen-centred' public administration moves the activity towards the public administration institutions by assuming a much greater deal of responsibility; ... public administration institutions realize the information-flow between themselves via back-office interconnection." (Bogdanoska Jovanovska, Erman \& Todorovski, 2013).

Infrastructure is the bloodstream of any city. Hence, Hall (2000) puts his focus on infrastructure and defines smart city as "a city that monitors and integrates conditions of all of its critical infrastructures, including roads, bridges, tunnels, rails, subways, airports, seaports, communications, water, power, even major buildings" and he explain that the purpose is optimization of the resources "plan its preventive maintenance activities, and monitor security aspects while maximizing services to its citizens". In that direction, Washburn et al. (2010) define smart city as "the use of Smart Computing technologies to make the critical infrastructure components and services of a city-which include city administration, education, healthcare, public safety, real estate, transport, and utilities-more intelligent, interconnected, and efficient".

According to all definitions previously mentioned, our working definition of smart city concept in this paper is as follows: a city that monitors and integrates the conditions of its road infrastructure, ensures better optimization of the resources, plans its preventive maintenance activities, and monitors the safety aspects, such as self-monitoring and a self-response system, by using Smart Computing technologies with the purpose of maximizing the services to its citizens in this area.

The European smart city model 3.0 (2014) has introduced six characteristics, built on the smart combination of endowments and activities of self-decisive, independent and aware citizens that make one city smart: Smart Governance, Smart Economy, Smart People, Smart Mobility, Smart Environment and Smart Living. According to Taylor (2015) and Gil-Garcia et al. (2015), Smart Governance relates the terms smart city and government. According to them, the increasing in efficiency and effectiveness has been achieved through 
demonstrating innovation and intelligence by local governments, which indicates the connection of e-government with smart city. Gil-Garcia et al. (2015) identified: institutional arrangements, city administration, and public services, as sub-elements of the smart city, whether they were referring to the economy, people, environment, living or mobility/transport.

\section{Transport and Smart Cities}

A core function of the smart cities is transport (Schlingensiepen et al. 2015). Transport systems and their efficiency are key factors in urban productivity. The correlation between transport systems and urban productivity is rather strong: urban productivity depends directly on the transport-related problems. The most common urban traffic problems in the cities are traffic congestion, increased demand for parking, public transport problems, difficulties for non-motorized transport, environmental impacts, and energy consumption, traffic safety. Solving such problems is a major challenge for the local government that strives to become a smart city.

Anthopoulus and Reedick (2016) point out that "smart (local) government runs smart city development". In transport solutions, this means that smart government activities include the designing of documentation related to smart city development: smart city policies, smart city strategies, smart city action plans, procedures, etc. Those activities have to achieve service design that fit the idea of smart city in any smart city area including transport by engaging citizens and all stakeholders as business and public institutions (including the process of Private Public Partnership) by using digital neighbourhood and information and communication technologies, as well as achieving a high level of standardization. Such activities require adjustment of the many already existing procedures and laws in certain areas or even creating new ones, where interoperability and data sharing among stakeholders are in the focus. Establishing new institutions mostly happens as part of this process.

\subsection{Smart mobility}

In order to handle the rapidly increasing population in the cities, the mobility solutions have to adapt and become smarter (MItchell, 2008). The smart 
mobilty solutions can be divided into three areas: Mass Transit Systems (MTS), Individual Mobility (IM) and Intelligent Transport Systems (ITS).

Train, subway or city buses are the primary mass transit systems. In order to provide efficient Bus Rapid Transit (BRT) following solutions have been implemented: buses priority at signalised intersections, Global Positioning System (GPS) technologies which monitor bus location and automatically adjust different right-of-way and traffic lights in real time that give priority to buses. Those types of solutions provide reducing of travel time, better environment quality and reduction in greenhouse gas emissions.

Towards individual mobility bicycles, carpooling, car sharing; and ondemand transport are some of the smart solutions. The principle of 'bicycle sharing' is very simple. A city resident picks up a bicycle (for a fee) from a given point $A$, uses it to get to another point $B$ and drops it off so that another resident can take it from Point $B$ to Point $C$ and so on. This concept is very popular in the European cities such as Amsterdam, Budapest, Paris, Ljubljana, etc. Carpooling and car sharing are concepts that are simple. Car sharing can be considered as car rental by the hour but is similar to 'biking' in that there are multiple pickup and drop-off points for the users. This concept can decrease the parking space demand in the city, whereas instead of multiple cars, a single car can do the work.

On-demand ride services are based on the concepts of sharing, convenience, and use of technology. Using of mobile or GPS in the process of reaching the passenger is much easier regarding the traditional taxi.

ITS integrate an IM and MTS options in an efficient manner by the implementation of sensors, connected cars, GPS-tracked public transport, adaptive traffic light, Closed-Circuit Television (CCTV) systems, navigation facilities, and, with the capability to integrate live data from most of these sources. These systems can decrease traffic congestion, improved traffic safety, and environment performances.

\subsection{The role of smart government in smart city transport solution}

According to Gil Garcia (2013), a smart city is only a subset of smart government, where local governments understand the term to 'being smart' as their attempts to enhance their efficiency, effectiveness, transparency and collaboration with emerging technologies and innovation. Harsh and Ichalkaranje (2015) present a claim that smart governments utilize the power of 'data' in their 
attempt to improve public services; to enable an integrated, seamless service experience; to engage with citizens; to co-develop policies, and to implement solutions for the well-being of the community. They adopt Rubels' (2014) definition for smart government according to which "government smart transformation engages citizen participation, information transparency, and service improvement". Maheshwari and Janssen (2014) recognize the need for public organizations' interconnection and discuss corresponding interoperability issues. This integration of information Gil-Garcia (2013) sees as a "whole-ofgovernment".

\section{Applying a smart city concept: key challenges for the Macedonian capital}

\subsection{Problems and Challenges}

The city of Skopje is not only the capital of the Republic of Macedonia but is also the country's largest city, housing approximately one third of the total population of Macedonia. According to the latest official census (2002), Skopje has 506,926 inhabitants, but the real number exceeds 600,000 inhabitants. The assessed number of people travelling to Skopje every day exceeds 90,000 .

A faster demographic expansion was caused by concentrating almost all state institutions in Skopje, resulting, enriched social, cultural, economic and political life. The lack of some infrastructural express streets forces unwanted interference of transit with non-transit traffic. The major road network has a total length of $211 \mathrm{~km}$. In combination with a high concentration of administrative and other service activities in the city's centre, and with a large number of people travelling to Skopje, traffic congestion, long queue, as well as driver frustration is an everyday picture on the urban network in the central area.

Considering that traffic problems affect the quality of life and economic prosperity of the city, the City of Skopje has started investing in urban traffic infrastructure (National Strategy 2009-2014). Empowered efforts towards amortizing the negative tendencies have been channelized through investments in smart transport solutions implemented through city projects. Financial support in the form of grants or loans from external as well as domestic sources played and still plays crucial importance in the process of achieving this goal. In this regard, worth mentioning are the projects in which Macedonia, and Skopje as a town, have taken part. The financial support of those projects (described in section 4.2) comes from the European Bank for Reconstruction and Development 
(EBRD) with Euro 2.6 million; the European Programme for Research and Development FP7 (project RENESSANSE) with Euro 220,000, as well as the technical support from the Austrian Government amounting to nearly Euro 700,000 (http://www.akademik.mk/foto-skopje-dobi-tsentar-za-regulirane-nasoobrakajot-4/).

\subsection{City projects and transport solutions}

The very first step that Skopje made on its way to becoming a smart city in the transport area was its participation in the RENESSANSE Project (Testing Innovative Strategies for Clean Urban Transport for Historic European Cities). It had four-year duration, in the period from 2008 to 2012, where one of the measures was that "the City should propose the creation of intelligent traffic management and control in the city centre of Skopje" (Bombol\&Koltovska, 2011). The City of Skopje has become the first city in Macedonia to have an adaptive traffic control system. Implementation of theadaptive traffic signal control system UTOPIA (Urban Traffic Optimization by Integrated Automation) as part of the FP7 project (2008-2012), where Skopje as city was a partner, had to demonstrate the operability of the Traffic Control Centre (TCC) by using an adaptive traffic control system for which it had been decided to be UTOPIA. The system was implemented in 2014. The main goals of this solution were the minimization of travel time through the network; decreasing time losses at intersections; diminishing environmental traffic impact; decreasing fuel consumption and increasing public transport (PT) travel speed. The preliminary evaluation results show to be very promising - thetravel time has been lowered by $20 \%$.

Later on, on the way to become a smart city in the area of mobility and transportation, Skopje started another project, so-called Skopje Velograd 2017 (Skopje Cycle city 2017). The activities within this project are directed in the area of Individual Mobility in the smart cities. The city's activities for implementing this project started in 2014, focusing on the improvement of the existent infrastructure and on the general promotion of cycling. The long-term goal of this project is to reduce emissions of greenhouse gases and to assist citizens in changing their primary mode of transport from cars to bicycles. In accordance with the project's objectives, by the year of 2017, $51 \mathrm{~km}$ of bike paths and lanes will have been reconstructed. The focus of the project is raising the citizens' awareness of responsible and environmentally friendly traffic behaviour. 
The project titled as Skopje E-City was also implemented. The capital city launched this project to enhance energy saving services and preserve the environment by using the power of new technologies and innovation. The city procured two e-chargers for two of the city multi-storey garages, intended for public use for charging e-vehicles. Five e-vehicles (e-scooters) and 10 e-bikes were procured for greater mobility for tourist sightseeing within the city while, in June 2015, another 7 e-vehicles with a retro look and 20 more e-bikes were purchased. There is an ongoing procurement of electric bikes for the city administration. These initiatives are part of a greater project - within the next 3 years, through PPP (Private Public Partnership), the City of Skopje is planning to introduce E-Everywhere. This includes E-charge network construction of electric charging stations in Skopje (30, in the first year), at the Skopje-Ohrid highway petrol stations (100, in the second year) and in all major cities in Macedonia (a total of 250 in the third year). Also, E-taxi will be introduced - a new fully electric taxi rental service using state-of-the-art telemetric systems for route optimization and smart phone application for booking. Other user-friendly eservices will be implemented such as an E-share system for car sharing rental, Elease system for small electric car rental and E-shuttle system - all electric small buses (16 seats) providing shuttle routes between the city hubs to key retail centers.

The last started project is Automatic Vehicle Location (AVL) System in Public Transport. As of January 1, 2016, an electronic ticketing and an Automatic Vehicle Location (AVL) system have been put into use within Skopje public transport buses. Electronic bus tickets became available in private transport buses on May 1, 2016. So far, the equipment has been installed in 377 public transport buses, including GPS systems, valuators, fiscal devices, audio announcement devices, displays, etc.

\subsection{Institutional smart government solution}

Within the frameworks of establishing the smart city fundaments in Skopje in the area of transport and smart mobility, has been established a new public institution - Traffic Control Centre (TCC) (http://maxim.mk/fotopromoviran-centarot-za-upravuvanje-i-kontrola-na-soobrakjajot, available at 01.11.2016). The idea for establishing this new institution occurred during the realization of the already mentioned FP7 project (described in Section 4.2). This Centre was established using the examples of the other centers that have already implemented the smart city concept, with the purpose to accept, store, 
process, and manipulate data from different sources related to transport and, based on this, control the traffic in Skopje.

Traffic Control Centre is organized based on the highest standards and its structure includes control and meeting room, manager and system administrator office, electric and network installations, video wall set, and software. The TCC's hardware consists of:

- Servers (application, communication, data, office and video server)

- Network equipment (routers, switches, firewall)

- Workstations (computers with four monitors)

- Video wall (5x2 monitors)

- Phone switchboard and satellite TV

- Printers, laptop, LCD projector

- UPS, generator, GPS aerial, devices for access control

The software installation consists of WEB ITC (signal controller management), EyeControl (for video wall management), BOSCH Client (for CCTV management), MXView (for data transfer network management), VISSIM (micro simulation software). There is a lack of information regarding human resources employees (operators) in the TCC.

The main functions of the Traffic Control Centre are: obtaining traffic data in real time, regulation of the lights system, visual observation of the traffic, giving priority to the public transport and information in real time for drivers. For this purpose, detectors and sensors have been installed at 90intersectionson the roads, as well as 50 cameras for visual monitoring of the traffic flows and 47 new lights controllers. An optical network for data transfer has also been installed with the aim of establishing a connection between the intersections and the Center. Furthermore, 5 traffic signs with variable messages have been implemented in order to inform the drivers about the traffic conditions in real time. This modern traffic control centre makes travelling in the city more convenient and also improves road safety.

Today, this Centre is fully functional and is the first example of an ITbased advanced traffic management and control system in Macedonia. This Centre constitutes a solid base for the introduction of new incoming solutions such as Smart Parking or Smart Free Parking System in the Skopje centre, as well as Share Transport solutions. 


\section{Discussion and Concluding Remarks}

New information and communication technology as an unsurpassable part of human lives creates a possibility for the transformation of traditional to smart cities. This transformation contributes to reducing spatial distances, organizing a high level of mobility and improving the quality of live in the cities, which poses a constant challenge for providing quality public services that are accessible to all citizens. But, although transformation of the cities' traditional management model into smart city models 'is not just an opportunity, but an imperative', Macedonia, just as many other developing countries, lags behind in this trend. The Skopje case study presented in this paper confirms that the goals of the traditional cities to become smart cities are not easily and quickly achievable nevertheless, what is most important is that the first steps have been made already.

The highly dense population of Skopje stresses the need for providing high-quality public transport services to the citizens, but also for the visitors and businesses achieving smart mobility and transport. The concept of smart mobility and transport, as one of the pillars of the smart city, has taken a significant place in the projects that have been realized in Skopje in the last few years. The implementation of the projects/smart solutions has led to public transport was promoted, as was the managing of transport demand and reducing of the traffic jams. Additionally, the implemented solutions created the need for establishing a new public institution for traffic regulation.

To sum up, owing to the implementation of the above-mentioned projects, Skopje has made significant progress in its efforts to become a smart city. However, critical analysis of the current situation has detected a lack of respect for some of the basic e-government principles, such as transparency or informativeness: e.g. the Traffic Control Centre has no web page, which means there is a lack of information about its functioning, contact details, the manner of operation, etc. The analysis has also indicated an absence of legal regulations related to this matter (a law on founding the Centre, a law on the interinstitutional exchange of information related to the work of this Centre). On the other hand, two questions remain open: 1 ) Is it enough to have such a modern centre without having anintegrated institutional relatedness?, and (if the answer is 'no') 2) How can we integrate all relevant institutions and stakeholders so as to ensure greater benefit for the entire community? Namely, at a time when talking 
about environmental protection is becoming increasingly loud, the smart infrastructure installed in the city of Skopje can be upgraded by introducing new smart solutions that would help decrease environmental pollution.

Consequently, as a way to move forward, the authors suggest mapping and integrating all relevant institutions and stakeholders in Skopje that need to be involved in the process of smart mobility and transport realization. They stress that the e-government's G2G pillar should be taken into account as the basis for this proposal and that well-defined back-office solutions will offer full integration of the traffic system in Skopje, thus creating the basis for future smart solutions in this field.

\section{References}

[1] Anthopoulos, L. \& Reddick, G. C. (2016). Smart City and Smart Government: Synonymous or Complementary? WWW'16 Companion, April 11-15, 2016, Montréal, Québec, Canada. ACM 978-1-4503-4144-8/16/04. DOI: http://dx.doi.org/10.1145/2872518.2888615.

[2] Allwinkle, S., \& Cruickshank, P. (2011). Creating Smarter Cities - An Overview. Journal of Urban Technology 18 (2), 1-16.

[3] Bogdanoska Jovanovska, M., Erman N., \&Todorovski, Lj. (2013). Evaluating the Maturity Level of e-Government Back-Office with Social Network Analysis. The 21st NISPAcee Annual Conference 2013 on Regionalisation and Inter-regional Cooperation. Belgrade, Serbia, 16-18 May 2013. full-paper published in conference proceedings.

[4] Bombol,K., \& Koltovska, D. (2011). Intelligent Traffic Management and Control in the City Centre of Skopje .ISEP 2011. Ljubljana.Slovenia.

[5] Caragliu, A., Del Bo, C., \& Nijkamp, P. (2009). Smart cities in Europe. In Proceedings of the 3rd Central European Conference in Regional Science (Košice, Slovak Republic, Oct 7-9). Available at http://www.cers.tuke.sk/cers2009/PDF/01_03_Nijkamp.pdf.

[6] Chourabi, H., Gil-Garcia, J. R., Prado, A. T., Nam, T., Mellouli, S., Scholl, H. J., Walker, S., \& Nahon, H. (2013). Understanding Smart Cities: An Integrative Framework. 45th Hawaii International Conference on System Sciences. DOI 10.1109/HICSS.2012.615.

[7] European Commission. (2013). Financing Models for Smart Cities, Smart Cities Stakeholder Platform. Finance Working Group. Guidance Document.

[8] European Smart City Model 3.0. https://eusmartcities.eu/sites/all/files/Guideline\%20Financing\%20Models\%20for\%20smart\%20citiesjanuary.pdf.

[9] Gibson, D.V., Kozmetsky, G., \& Smilor, R.W. (1992). The Technopolis Phenomenon: Smart Cities, Fast Systems, Global Networks. Rowman \& Littlefield.

[10] Gil-Garcia, J. R. (2013). Towards a smart State? Inter-agency collaboration, information integration, and beyond. In Meijer, A.J., Bannister, F. and Thaens, M. (Eds) ICT, Public Administration and Democracy in the Coming Decade, Innovation and the Public Sector Series, 20, 59-70, IOS Press BV: Amsterdam. 
[11] Gil-Garcia, J.R., Pardo, T.A. \& Nam, T. (2015). What makes a city smart? Identifying core components and proposing an integrative and comprehensive conceptualization. Information Polity, 20(1), 61-87.

[12] GSMA Smart City (2013). Guide to Smart City: The Opportunity for Mobile Operators. London. UK. February 2013. Version 1.0 http://www.gsma.com/connectedliving/wpcontent/uploads/2013/02/cl_sc_guide_wp_02_131.pdf.

[13] Hall, R. E. (2000). The vision of a smart city. In Proceedings of the 2nd International Life Extension Technology Workshop, Paris, France, September 28, Available from http://www.osti.gov/bridge/servlets/purl/773961-oyxp82/webviewable/773961.pdf.

[14] Harsh, A. \& Ichalkaranje, N. (2015). Transforming eGovernment to Smart Government: A South Australian Perspective. Advances in Intelligent Systems and Computing, 1, 9-16.

[15] Harrison, C. \& Abbott Donnelly, I. (2011). A Theory of Smart Cities. White Paper.

[16] Maheshwari, D. \& Janssen, M. (2014). Reconceptualizing measuring, benchmarking for improving interoperability in smart ecosystems: The effect of ubiquitous data and crowdsourcing. Government Information Quarterly, 31, S84- S92.

[17] Manville, C., Cochrane, G., Cave, J., Mellard, J., Pederson, J. K., Thaarup, R. K., Liebe, A., Wissner, M., Massink, R., and Kotterink, B. (2014) Mapping Smart Cities in the EU. Study. Directorate General for Internal Policies. Policy Department A: Economic and Scientific Policy. RAND Europe, Danish Technological Institute, WiK, and TNO. IP/A/ITRE/ST/2013-02 January 2014, PE 507.480 EN

[18] MItchell, J. W. (2008). Mobility on Demand: Future of transportation in cities. Smart Cities. MIT Media Laboratory. Massachusetts Institute of Technology.

[19] Nam, T. and Pardo, A. T. (2011). Conceptualizing Smart City with Dimensions of Technology, People, and Institutions. The Proceedings of the 12th Annual International Conference on Digital Government Research

[20] Natural Resources Defense Council. What are smarter cities? Available from.http://smartercities.nrdc.org/about (Accessed at 10.10.2016).

[21] National Strategy 2009 - 2014, Macedonia to Promote Safety Road Traffic http://studiorum.org.mk/h2020mkd_upload/upload/Nacionalna\%20strategija\%20za \%20unapreduvanje\%20na\%20bezbednosta\%20na\%20soobrakjajot\%20na\%20patishtata.pdf

[22] Schlingensiepen, J., Mehmood, R. and Nemtanu, C. F. (2015): Framework for an Autonomic Transport System in Smart Cities. Bulgarian Academy of Sciences Cybernetics and Information Technologies. Volume 15, No 5 Special Issue on Control in Transportation Systems Sofia, 2015 Print. ISSN: 1311-9702; Online ISSN: 1314-4081 DOI: 10.1515/cait-20150016.

[23] Taylor, J.A. (2015). The Art of the Possible: Innovation, smart government and the enduring braking-power of traditional public administration. Information Polity, 20, 1-2.

[24] Volpe, A. J. (2014). The Smart/Connected City and Its Implications for Connected Transportation. White paper. National Transportation Systems Center. U.S. Department of Transportation. Intelligent Transportation Systems Joint Program Office FHWA-JPO-14-148. www.its.dot.gov/index.htm.

[25] Washburn, D., Sindhu, U., Balaouras, S., Dines, R. A., Hayes, N. M., \& Nelson, L. E. (2010). Helping CIOs Understand "Smart City" Initiatives: Defining the Smart City, Its Drivers, and the Role of the ClO. Cambridge, MA: Forrester Research Inc. Available from http://public.dhe.ibm.com/partnerworld/pub/smb/smarterplanet/forr_help_cios_und_smar t_city_initiatives.pdf. 
HOLISTICA Vol 8, Issue 1, 2017

[26] http://www.akademik.mk/foto-skopje-dobi-tsentar-za-regulirane-na-soobrakajot-4/, available at 01.11.2016

[27] http://maxim.mk/foto-promoviran-centarot-za-upravuvanje-i-kontrola-na-soobrakjajot, available at 01.11.2016 